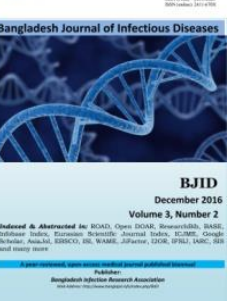

\title{
Findings of Brain Imaging among Tuberculous Meningitis Patients: A Study of 30 Cases in Bangladesh
}

\author{
Abul Kalam Mohammed Shoab ${ }^{1}$, Mostafa Hosen ${ }^{2}$, Syed Abul Foez ${ }^{3}$, Md. Shaheen Wadud ${ }^{4}$, \\ Habibur Rahman ${ }^{5}$,Shahjada Mohammad Dastegir Khan ${ }^{6}$, Masud Rana ${ }^{7}$, Biplob Kumar Roy ${ }^{8}$
}

\begin{abstract}
${ }^{1}$ Assistant Professor, Department of Neurology, MAG Osmani Medical College, Sylhet, Bangladesh; ${ }^{2}$ Assistant Professor, Department of Neurology, MAG Osmani Medical College, Sylhet, Bangladesh; ${ }^{3}$ Assistant Professor, Department of Hepatology, MAG Osmani Medical College, Sylhet, Bangladesh; ${ }^{4}$ Assistant Professor, Department of Neurology, Dhaka National Medical College, Dhaka, Bangladesh; ${ }^{5}$ Assistant Professor, Department of Endocrinology, MAG Osmani Medical College, Sylhet, Bangladesh; ${ }^{6}$ Assistant Professor, Department of Neurology, Sir Salimullah Medical College, Dhaka, Bangladesh; ${ }^{7}$ Assistant Professor, department of Neurology, BSMMU, Dhaka, Bangladesh; ${ }^{8}$ Professor, department of Neurology, Sylhet M A G Osmani Medical College, Sylhet, Bangladesh
\end{abstract}

[Received: 17 March 2018; Accepted: 12 April 2019; Published: 1 June 2019]

\begin{abstract}
Background: Tuberculous meningitis is a serious health hazard and difficult to diagnose. Objectives: The purpose of the present study was to observe the role of CT/MRI in TBM diagnosis. Methodology: This was a retrospective study done from January 2010 to December 2011 for a period of two (02) years. Patients of TBM were reviewed in a medical college hospital of Bangladesh. Results: A total number of reviewed 30 TBM patients; among them 11 cases were confirmed TBM patients and 19 were probable patients. Brain imaging (CT/MRI) was performed in 15 cases. The use of brain imaging allowed the Brain lesions in $93.3 \%$ patients. Conclusion: Brain imaging was done in 15 out of 30 TBM patients and most of them (14/15) had got various forms of radiological abnormalities that aid in diagnosis and monitor of disease progression in TBM. [Bangladesh Journal of Infectious Diseases, June 2019; 6(1):8$11]$

Keywords: Tuberculous meningitis; TBM; Cerebrospinal fluid; CSF; CT-scan; MRI

Correspondence: Dr. Abul Kalam Mohammed Shoab, Assistant Professor, Department of Neurology, MAG Osmani Medical College, Sylhet, Bangladesh; Cell no.: +8801718067810; Email: shoabmcpsbcsmd@ gmail.com

Conflict of interest: There is no conflict of interest to any of the authors of this article.

Funding agency: The study was not funded by any authority.

Contribution to authors: AKMS, MH, SAF, MSW and HR involved in protocol preparation, data collection and literature search up to manuscript writing. SMDK and MR involved in preparation and revision of this manuscript.

How to cite this article: Shoab AKM, Hosen M, Foez SA, Wadud MS, Rahman H, Khan SMD, Rana M, Roy BK. Findings of Brain Imaging among Tuberculous Meningitis Patients: A Study of 30 Cases in Bangladesh. Bangladesh J Infect Dis 2019;6(1):8-11

Copyright: (02019. Shoab et al. Published by Bangladesh Journal of Infectious Diseases. This article is published under the Creative Commons CC BY-NC License (https://creativecommons.org/licenses/by-nc/4.0/). This license permits use, distribution and reproduction in any medium, provided the original work is properly cited, and is not used for commercial purposes.
\end{abstract}




\section{Introduction}

TBM is the severe form of extra-pulmonary tuberculosis occurring $7.0 \%$ to $12.0 \%$ of $\mathrm{TB}$ patients $^{1}$. Delay in diagnosis and so in the start of effective treatment results in poor prognosis and sequlae in up to $25 \%$ of cases. Diagnosis is difficult and based on clinical and biological features, and disease progression ${ }^{2}$. A good prognosis depends on early diagnosis and treatment; therefore we focus herein the importance of radiological findings.

\section{Methodology}

This was retrospective study. In this study TBM patients were reviewed who were diagnosed and were treated at the department of Medicine at Sir Salimullah Medical College and Mitford Hospital, Dhaka, Bangladesh from January 2010 to December 2011 for a period of two (02) years. Among these 30 patients, 15 patients had done brain imaging (CT/MRI) with or without contrast according to findings. CT was done in the axial plane and MRI 1 tesla strength with T1, T2, T2 inversion sequlae with Gadolinium IV injection as needed. The diagnosis of TBM was made on the basis of following criteria: clinically confirmed cases: Mycobacterium tuberculosis in CSF by staining and/or culture. Clinically suspected patients (TBM): Negative cultures with subacute or chronic fever with meningeal irritation (headache, neck stiffness) and vomiting, with or without other features of CNS involvement. CSF: raised protein levels, and/or decreased glucose (CSF: blood glucose ratio <0.5), and/or pleocytosis with lymphocytic predominance. Clinical response to anti-tuberculous drugs. The stage of TBM was determined by the method of Gordon and Parson ${ }^{12}$ : at stage 1 the patient is fully conscious, at stage 2 the patient is drowsy or has focal neurological signs, and at stage 3 the patient is comatose or nearly so. Patients were monitored with monthly clinical examination for three months and finally follow up was done at medicine OPD and over the telephone.

\section{Results}

Thirty patients with TBM were recorded for this study of which 18 cases were male and 12 cases were female. The age range was 16 to 85 years with the mean of 30.57 years of which $11 / 30(36.67 \%)$ was age group of $15-20$ years and 6/30(20\%) was age group of 21-29 years and also 30- 39 years. However $>50$ years was only $2(6.67 \%)$ of TBM patients. Only 11 patients were diagnosed as confirmed TBM by culture positivity and rest of 19 patients were probable TBM.

Table 1: Distribution of the Respondents by Age $(\mathrm{n}=30)$

\begin{tabular}{|l|c|c|}
\hline Age Group & Frequency & Percent \\
\hline 15 to 20 Years & 11 & 36.67 \\
\hline $21-29$ & 6 & 20 \\
\hline $30-39$ & 6 & 20 \\
\hline $40-50$ & 5 & 16.67 \\
\hline$>50$ & 2 & 6.67 \\
\hline Total & 30 & 100 \\
\hline Mean \pm SD (Range) & \multicolumn{2}{|c|}{$30.57 \pm 15.70(16-85)$} \\
\hline
\end{tabular}

Clinical data: At presentation, fourteen patients were classified as being at Gordon and Parson Stage 1,12 at stage 2 and 4 at stage 3 . Cranial nerve palsies were noted before therapy in six cases; other focal neurological signs were noted in eleven patients. Neck rigidity and Kerning's sign were present in $27(90 \%)$ and 15(50\%) respectively. Among the study subjects $10 \%$ had GCS score less than $8,18.3 \%$ had between 9 to 12 and $71.7 \%$ had over $>12$. Neurological deterioration was noted in 2 patients under treatment and died eventually due to delay of treatment and stage 3 presentations. The study subjects showed papilloedema in 8 patients and bilateral optic atrophy in 2 patients. There were one or more tuberculous location in 8 patients; 1 in cervical lymph node, 5 in pulmonary tuberculosis and 2 retinal involvement. The anti-tuberculous regimen was isoniazid $5 \mathrm{mg} / \mathrm{kg} / \mathrm{day}$, rifampin 10 $\mathrm{mg} / \mathrm{kg} /$ day, ethambutol $20 \mathrm{mg} / \mathrm{kg} / \mathrm{day}$, and pyrazinamide $30 \mathrm{mg} / \mathrm{kg} / \mathrm{day}$ for two months. This was followed by isoniazid with rifampin ( $\mathrm{INH}-$ RMP) for 12 to 24 months according to status of TBM. Corticosteroids (prednisolone) were used with stage 2 and 3 patients, at doses of 0.5 to 1 $\mathrm{mg} / \mathrm{kg} /$ day with progressively decreasing doses for 2 to 3 months.

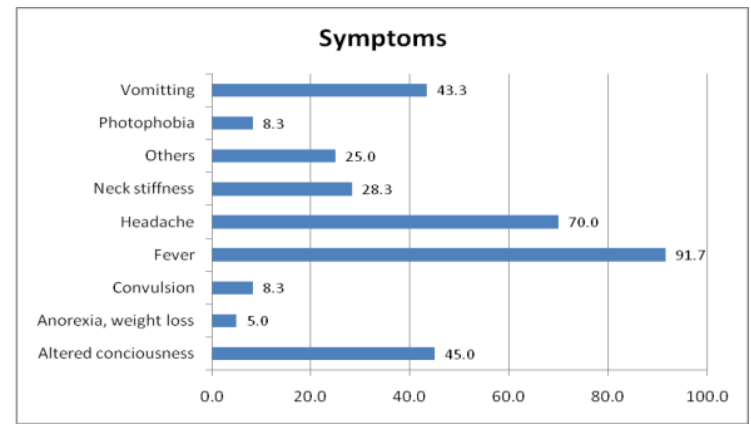

Figure I: depicts the distribution of the study subjects by presenting symptoms. 
In this study most prevalent symptom was fever (91.7\%). Among others Headache $(70 \%)$, altered consciousness (45\%), Vomiting $(43.3 \%)$ and neck stiffness $(28.9 \%)$ were notable.

Laboratory Data: The CSF was clear or xanthochromic in all cases with the total WBC count ranging from 5 to $6400 / \mathrm{cmm}\left(484.7+\right.$ _ $\left._{\text {1 }} 1317\right)$ with a lymphocytic predominance in all cases. The CSF glucose level was low in all cases, and CSF protein level was elevated in most cases with a range of $37-1440 \mathrm{mg} / \mathrm{dl}$ at presentation. CSF culture (Lowenstein-Jensen media) was positive in 11 patients.

Table 2: Biochemical parameters of CSF in TBM (n-30)

\begin{tabular}{|l|c|c|}
\hline Variables & Mean \pm SD & Range \\
\hline Sugar $(\mathrm{mmol} / \mathrm{L})$ & $2.6 \pm 1.2$ & 0.8 to 6.5 \\
\hline Protein $(\mathrm{mg} / \mathrm{dl})$ & $212.3 \pm 275.1$ & 37 to 1440 \\
\hline TC $(/ \mathrm{cmm})$ & $484.7 \pm 1317$ & 5 to 6400 \\
\hline Lymphocyte $(\%)$ & $72.08 \pm 31.2$ & 10 to 100 \\
\hline Polymorph $(\%)$ & $28.12 \pm 31.6$ & 0 to 95 \\
\hline
\end{tabular}

Table shows the biochemical parameters of CSF in $\mathrm{TBM}$.The data are expressed as mean $\pm \mathrm{SD}$ with range.

Radiological data: CT/MRI of brain was done in 15 out of 30 patients of TBM and most of them (14/15) had got radiological abnormalities (93.3\%). CT was done in 7 patients on the other hand MRI in 8 patients and Isolated hydrocephalus was seen in 5 ,tuberculoma in 4,inarct in 1 , mixed lesion(hydrocephalus with infarct/ tubeculoma) in 4 patients.

Table 3: Radiological findings of Brain Imaging in TBM patients

\begin{tabular}{|l|c|c|}
\hline $\begin{array}{l}\text { Brain Imaging } \\
\text { Findings(CT/MRI) }\end{array}$ & $\begin{array}{l}\text { Frequen } \\
\text { cy }\end{array}$ & Percent \\
\hline Isolated Hydrocephalus & 5 & 33.3 \\
\hline Tuberculoma & 4 & 26.6 \\
\hline Infract & 1 & 6.6 \\
\hline $\begin{array}{l}\text { Mixed (Hydrocephalus } \\
\text { with infract/tuberculoma) }\end{array}$ & 4 & 26.6 \\
\hline Normal & 1 & 6.6 \\
\hline Total & $\mathbf{1 5}$ & $\mathbf{1 0 0}$ \\
\hline
\end{tabular}

Tuberculoma, arachnoiditis, external pachy-mening -itis had a low T1 image, a high signal in T2, and were enhanced after gadolinium injection.

Clinical outcome: Stage 1 patients (14) had a good outcome without any complications; stage 2 patients (12) improved after an initial neurological deterioration and stage 3 patients (4) had poor outcome -2 died during the treatment period.

Table 4: Staging of TBM patients and clinical outcome (n-30)

\begin{tabular}{|l|c|l|}
\hline $\begin{array}{l}\text { Stage of } \\
\text { TBM }\end{array}$ & $\begin{array}{c}\text { Number } \\
\text { of Patients }\end{array}$ & Outcome \\
\hline 1 & 14 & Good \\
\hline 2 & 12 & $\begin{array}{l}\text { Improved after initial } \\
\text { deterioration }\end{array}$ \\
\hline 3 & 4 & Poor (2 died) \\
\hline
\end{tabular}

\section{Discussion}

TBM remains a life-threatening disease with the prognosis dependent on initial presentation and on treatment delay ${ }^{4}$. This is why it is emphasized herein the importance of early diagnosis. Bangladesh ranks $6^{\text {th }}$ out the list of 22 countries where burden imposed by TB is high ${ }^{5}$. TBM is the severe form of extra-pulmonary $\mathrm{TB}$ and in the absence of an early diagnosis and treatment, high mortality (20-30\%) Kashyap et $\mathrm{al}^{6}$. In this study clinical presentation was classic: sub acute course, disorientation, history of fever in most cases $(91.7 \%)$ that was low grade, evening rising, associated with night sweats. In other study the incidence was $87 \%$ and $58.9 \% \%^{7-8}$. Meningeal irritation was seen in $27(90 \%)$ patients as neck rigidity and $15(50 \%)$ as Kernig's sign that was $54 \%$ and $40 \%$ in other study ${ }^{7}$. Early diagnosis is important to avoid morbidity and mortality ${ }^{7}$. When a definite diagnosis relies on a CSF positive culture for Mycobacterium tuberculosis (20.0\% to 50\%), on the presence of AFB on CSF smear (12.5\% to $45.0 \%$ ), diagnosis is frequently presumptive ${ }^{2}$. To improve on these, and make a definite diagnosis, many methods can be used. These require specialist laboratories, incurring high costs a barrier for developing countries. PCR of CSF is a good sensitivity $80.0 \%$ to $91.0 \%$; however, it is limited due to high expense and unavailability ${ }^{2}$. Brain imaging (MRI of Brain) findings are not specific but when associated with clinical and biological parameter, they are suggestive and can be a good method of diagnosis assessment ${ }^{11}$.

In this study brain imaging (CT/MRI) were done in 15 patients out of 30 patients due to raised ICP with 
focal neurological deficit and initial poor response to anti-TB. CT was done in 7 patients on the other hand MRI in 8 patients with the findings of isolated hydrocephalus in 5 cases, tuberculoma in 4 cases, infarct in 1 case, mixed lesion (hydrocephalus with infarct or tuberculoma) in 4 patients. Out of 9 hydrocephalus patients 5 had done VP shunt from neurosurgery department, one died at home after one month and rest of them improved. CT rather than MRI was done in 7 patients due to patient's poor compliance. The reason behind CT/MRI of brain was not done in 15 cases were followings: 5 patents had associated pulmonary TB, 1 had cervical lymph node TB (Biopsy positive for MTB), 9 were stage 1 with early response to Anti TB and lastly one died at very beginning due to ARDS. That patient was a CSF culture positive TBM and diagnosed after 6 weeks of death. Abdelmalek et $\mathrm{al}^{11}$ got MRI abnormality in $89.6 \%$. When TBM is suspected, treatment should be started immediately, without waiting for a definite diagnosis 13 cases. In this study, treatment delay was associated with death in two cases and with neurological worsening in 15 cases; two of them got permanent vision loss due to optic atrophy.

Treatment duration is variable, ranging from 9 to 24 months ${ }^{4,12}$. There is considered 12 months to be the minimum treatment duration for TBM due to the poor diffusion of anti-tuberculous drugs into the CSF and in tuberculoma. Corticosteroids must be used for at least six weeks, mainly in patients at Gordon and Parson stage 2, to prevent complications, to reduce duration of symptoms and frequency of sequelae, and to improve survival ${ }^{12}$.

In this study there is a limitation that it was not possible to collect CT /MRI films as patients party took it with them during discharge rather we have only the data of radiological reports of both CT and MRI.

\section{Conclusion}

Most of the study population have got radiological abnormalities in various form. Therefore, it is concluded that in tuberculous meningitis brain imaging is a good method to strengthen diagnosis and to monitor disease progression, especially in developing countries where definite diagnosis by laboratory testing is limited.

\section{References}

1. Rana SV, Singh RK, Singh K, Kumar L. Adenosine deaminase levels in cerebrospinal fluid as a diagnostic, test for tuberculous meningitis in children, Indian $\mathbf{J}$ Clinbiochem. 2004;19:5-9

2. Narayanan S, Parandaman V, Narayanan PR, Venkatesan P, Girish C, Mahadevan S, et al. Evaluation of PCR using TRC4 and IS6110 primers in detection of tuberculous meningitis. J Clin Microbiol 2001;39:2006-8

3. Kashyap RS, Kainthla SA, Mudaliar AV. Cerebrospinal fluid adenosine deaminase activity: a complimentary tool in the early diagnosis of tuberculous meningitis. Cerebrospinal Fluid Res 2006;30;3-5

4. Grimaud-Ayina M, Fain O, Lortholary O, Cruaud P, Kettaneh A, Stirnemann J, et al. La tuberculose neurome'ninge'e dans la banlieue nord-est de Paris. Ann Med Interne 2002;153: 75-81

5. World Health Organization, Global tuberculosis Control 2009: a short update to the 2009 report, HO/HTM/TB/2009.426. Geneva: World Health Organization, 2009

6. Kashyap RS, Kanthia RP, Satpute RM, Agarwal NP, Chandak NH, Purohit HJ, et al. Differential diagnosis of tuberculous meningitis from partially treated pyogenic meningitis by cell ELISA. BMC Neurol 2004;4;16

7. Katti MK. Pathogenesis, diagnosis, treatment, and outcome aspects of cerebral tuberculosis. Med Sci Monit 2004;10:215-229

8. Chotmongkol V, Teerajetgul Y, Yodwut C. Cerebrospinal fluid adenosine deaminase activity for the diagnosis of tuberculous meningitis in adults. Southeast Asian Journal of Tropical Medicine \& Public Health. 2006;37(5):948

9. Narayanan S, Parandaman V, Narayanan PR, Venkatesan P, Girish C, Mahadevan S, et al. Evaluation of PCR using TRC4 and IS6110 primers in detection of tuberculous meningitis. J Clin Microbiol 2001;39:2006-8

10. Grimaud-Ayina M, Fain O, Lortholary O, Cruaud P, Kettaneh A, Stirnemann J, et al. La tuberculose neurome'ninge'e dans la banlieue nord-est de Paris. Ann Med Interne 2002;153: 75-81

11. Abdelmalek R, Kanoun F, Kilani B, Tiouiri H, Zouiten F, Ghoubantini A, Chaabane TB. Tuberculous meningitis in adults: MRI contribution to the diagnosis in 29 patients. International journal of infectious diseases. 2006;10(5):372-7.

12. Ramachandran TS. Tuberculous Meningitis, Chief Editor: Karen L Roos; 2011, Medscape; http://emedicine.medscape.com/article/1166190 